\title{
Failure Analysis of Multilayered Suspension Plasma-Sprayed Thermal Barrier Coatings for Gas Turbine Applications
}

\author{
M. Gupta ${ }^{1}$ N. Markocsan ${ }^{1}$ R. Rocchio-Heller ${ }^{2} \cdot$ J. Liu $^{2} \cdot$ X.-H. Li ${ }^{3}$ \\ L. Östergren ${ }^{4}$
}

Submitted: 16 July 2017 / in revised form: 8 November 2017/Published online: 2 January 2018

(c) The Author(s) 2017. This article is an open access publication

\begin{abstract}
Improvement in the performance of thermal barrier coatings (TBCs) is one of the key objectives for further development of gas turbine applications. The material most commonly used as TBC topcoat is yttriastabilized zirconia (YSZ). However, the usage of YSZ is limited by the operating temperature range which in turn restricts the engine efficiency. Materials such as pyrochlores, perovskites, rare earth garnets are suitable candidates which could replace YSZ as they exhibit lower thermal conductivity and higher phase stability at elevated temperatures. The objective of this work was to investigate different multilayered TBCs consisting of advanced topcoat materials fabricated by suspension plasma spraying (SPS). The investigated topcoat materials were YSZ, dysprosia-stabilized zirconia, gadolinium zirconate, and ceriayttria-stabilized zirconia. All topcoats were deposited by TriplexPro- $210^{\mathrm{TM}}$ plasma spray gun and radial injection of suspension. Lifetime of these samples was examined by thermal cyclic fatigue and thermal shock testing. Microstructure analysis of as-sprayed and failed specimens was performed with scanning electron microscope. The failure mechanisms in each case have been discussed in
\end{abstract}

This article is an invited paper selected from presentations at the 2017 International Thermal Spray Conference, held June 7-9, 2017, in Düsseldorf, Germany, that has been expanded from the original presentation.

M. Gupta

mohit-kumar.gupta@hv.se

1 University West, Trollhättan, Sweden

2 Oerlikon Metco, Westbury, NY, USA

3 Siemens Industrial Turbomachinery AB, Finspång, Sweden

4 GKN Aerospace, Trollhättan, Sweden this article. The results show that SPS could be a promising route to produce multilayered TBCs for high-temperature applications.

Keywords burner rig testing · failure mechanism . lifetime - multilayered thermal barrier coatings . suspension plasma spraying - thermal cyclic fatigue

\section{Introduction}

Development of thermal barrier coatings (TBCs) allowing higher combustion temperatures is of great interest for all gas turbine manufacturers since it results in a more efficient combustion which in turn results in higher fuel efficiency as well as environmentally cleaner emissions. The most commonly used TBC material is yttria-stabilized zirconia (YSZ). YSZ has been used extensively for the past thirty years due to its favorable thermal and mechanical properties. However, at operating temperatures above $1200{ }^{\circ} \mathrm{C}$, YSZ undergoes phase transformation with increase in volume which leads to increased residual stress level in coatings and hence early failure of the TBC (Ref 1,2$)$. Moreover, at temperatures above $1200{ }^{\circ} \mathrm{C}$, the YSZ coatings also undergo sintering at a high rate and are susceptible to CMAS (calcium-magnesium-alumino-silicates) attack, both of which may significantly affect the TBC lifetime (Ref 3, 4).

New ceramic materials such as the pyrochlores, perovskites, and co-doped zirconia have been identified as alternative candidates to YSZ for high-temperature applications (Ref 5, 6). However, these materials usually exhibit a lower fracture toughness and thermal expansion coefficient than YSZ (Ref 7) and some of them (e.g., gadolinium zirconate) also have compatibility issues with the bondcoat 
Table 1 TBCs produced in this study

\begin{tabular}{lcc}
\hline Sample ID & Topcoat material (suspension ID)/coating thickness, $\mu \mathrm{m}$ \\
\hline YSZ & YSZ $(A E 10966) / 300$ & \\
DySZ & DySZ $(A E 10873) / 300$ & GZO $(A E 10874) / 200$ \\
YSZ/GZO & YSZ $(A E 10966) / 100$ & CeYSZ $(A E 10876) / 200$ \\
YSZ/CeYSZ & YSZ $(A E 10966) / 100$ & \\
\hline
\end{tabular}

layer due to oxidation at higher temperatures (Ref 8). In order to overcome these drawbacks, a multilayered TBC is preferably applied with a first layer of YSZ and top layer made of an advanced TBC material which can result in a significantly enhanced lifetime (Ref 9, 10). In this multilayer system, the YSZ layer provides a good fracture toughness close to the topcoat-bondcoat interface and high thermal expansion coefficient, while the subsequent material layers provide low sintering, high thermal stability and CMAS attack resistance (Ref 11). Studies done on these materials sprayed by atmospheric plasma spraying (APS) showed that multilayered thermal barrier coatings show good functional performances while their thermal properties can be well preserved (Ref 8, 11, 12).

Columnar microstructures produced by suspension plasma spraying (SPS) are of significant commercial interest as SPS offers a cheaper alternative than the conventionally used electron-beam physical vapor deposition (EBPVD) process, whereas the coatings' thermal conductivity and lifetime are preserved or even improved (Ref 1316). Multilayered TBCs produced by SPS are of high relevance for the gas turbine industry as they can allow higher combustion temperatures and enhanced functional performances.

In previous work done by Gupta et al. (Ref 17), thermal cyclic lifetime of SPS bilayer YSZ topcoat architecture with dense first layer followed by columnar second layer was compared to columnar single-layer YSZ. The experimental results showed that the bilayer TBC had a higher lifetime than the single-layer TBC. It was concluded based on modeling results that the first dense layer and column gaps are beneficial for lifetime as they reduce the thermally induced stresses (Ref 17). In other works done on SPS multilayered TBCs, Mahade et al. (Ref 18-20) studied two multilayered architectures: first with columnar gadolinium zirconate (GZO) sprayed on dense YSZ and second with an additional dense GZO layer on top of the first architecture, and compared these two TBCs with single-layer columnar YSZ TBC. It was shown that the multilayered TBCs resulted in a lower thermal conductivity and improved thermal cyclic fatigue life compared to the single-layer YSZ (Ref 18). It was also found that multilayered TBCs showed a different failure mode in thermal cyclic fatigue testing where the failure occurred in the columnar GZO layer close to the GZO-YSZ interface (Ref 19). The sintering resistance of SPS GZO layer was shown to be higher than YSZ (Ref 19). The multilayered TBCs also showed a higher lifetime in burner rig testing (Ref 20). These results indicate that multilayered TBCs with advanced materials fabricated by SPS can enhance the functional performance of TBCs. However, these results were limited to GZO as the only advanced topcoat material.

The objective of this work was to investigate the thermal cyclic lifetime of different single-layer and double-layer topcoat architectures deposited by SPS using three advanced topcoat materials namely dysprosia-stabilized zirconia (DySZ), GZO, and ceria-yttria-stabilized zirconia (CeYSZ). The failure mechanism under thermal cyclic testing conditions in each case was examined.

\section{Experimental}

\section{Sample Preparation}

Two topcoat architectures were investigated in this studysingle layer and bilayer. The single-layer topcoat architectures investigated were 8 wt.\% YSZ and 10 wt.\% DySZ, while the bilayer topcoat architectures investigated were GZO and CeYSZ sprayed on top of YSZ layer. The reason for selecting these architectures was to understand the influence of advanced materials on TBC performance in the form they would normally be applied in industry.

The total thickness of topcoats was kept the same as $300 \mu \mathrm{m}$ for all samples. In case of bilayer topcoats, the first layer deposited was $100 \mu \mathrm{m}$ in thickness, while the second layer was $200 \mu \mathrm{m}$ in thickness. All topcoats were sprayed by SPS using the TriplexPro- $210^{\mathrm{TM}}$ spray gun (Oerlikon Metco) and all suspensions were developed by Oerlikon Metco, Westbury, USA. The TBCs produced in this study are summarized in Table 1. All suspensions were made in ethanol with $25 \%$ solids load and similar particle size distributions. The spray parameters used for spraying topcoats in this study are given in Table 2 . As can be seen in Table 2, same spray parameters were used for all materials except the spray distances that were backed off on top layers of systems to reduce heat input and stress levels. While it may be argued that each of these materials may require an individual set of parameters to fully optimize 
Table 2 Spray parameters used for spraying the topcoats in this study

\begin{tabular}{ll}
\hline Gun & Triplex 210 \\
Nozzle & $9 \mathrm{~mm}$ \\
Current & $480 \mathrm{~A}$ \\
Plasma gases & $\mathrm{Ar}+\mathrm{H}_{2}$ \\
Plasma gas flow & $58 \mathrm{nlpm}$ \\
Suspension feed rate & $32 \mathrm{~g} / \mathrm{min}$ \\
Spray distance & YSZ: $64 \mathrm{~mm}$, DySZ: $70 \mathrm{~mm}, \mathrm{GZO}$ and CeYSZ: $76 \mathrm{~mm}$ \\
\hline
\end{tabular}

their microstructure, the spray parameters were not changed in this case (except spray distance) as it is difficult to interpret the results if too many variables are changed at the same time (changing both material and spray parameters) when comparing different TBCs.

The bondcoat material for all samples was NiCoCrAlY (AMDRY 386-2, Oerlikon Metco), while the substrate material was Hastelloy-X. The thickness of bondcoat was $150 \mu \mathrm{m}$. Button-shaped substrates in dimensions $25.4 \mathrm{~mm}$ diameter $\times 6 \mathrm{~mm}$ thickness were used for microstructure analysis and thermal shock testing, while for thermal cyclic fatigue (TCF) testing, plate substrates in dimensions $50 \mathrm{~mm} \times 30 \mathrm{~mm} \times 6 \mathrm{~mm}$ were used.

Preheating was done on all layers of each set of samples before spraying topcoats. Principles from prior multilayer systems were used while spraying where the first topcoat layer was sprayed slightly denser than the second topcoat layer (Ref 11).

\section{Microstructure}

For metallographic preparation, the samples were first cold-mounted in low-viscosity epoxy resin, then sectioned using a cutting disk, and cold-mounted again in high viscosity epoxy resin for polishing. The polishing was performed using an automated routine with a Buehler PowerPro 5000 equipment.

Microstructure of both as-sprayed as well as failed samples after lifetime testing was analyzed by scanning electron microscopy (SEM) using a Hitachi TM3000 tabletop SEM equipment.

\section{Porosity Measurement}

In this work, image analysis technique was used to evaluate the porosity in the TBCs. Since SPS coatings show porosity in a wide range from several micrometers to a few nanometers, image analysis was performed in two steps by taking SEM images at low and high magnifications similar to the approach undertaken by Ganvir et al. (Ref 13, 21). Images at low magnification $(500 \times)$ could capture large features in the coatings such as intercolumnar gaps, large cracks and micrometric pores, while the images at high magnification $(5000 \times)$ could capture the fine porosity mainly inside the columns. Ten images were taken at each magnification across the coating cross section. The images were processed using the open source software Fiji (ImageJ) (Ref 22). The images were first converted from grayscale to binary. Then the $500 \times$ images were filtered to contain porous features only larger than $2 \mu \mathrm{m}^{2}$ area, and the $5000 \times$ images were filtered to contain porous features only smaller than $2 \mu \mathrm{m}^{2}$ area. This step was performed to ensure that there is no overlapping of the porous areas between the $500 \times$ and $5000 \times$ images. The total porosity of the coating was then calculated by adding the coarse and fine porosity evaluated from the $500 \times$ and $5000 \times$ images, respectively.

\section{Thermal Cyclic Fatigue Testing}

TCF testing is performed to analyze the performance of TBCs under long exposures at high temperature. This test allows for significant oxide growth due to bondcoat oxidation. The failure in TCF testing is mainly driven by crack propagation due to swelling of thermally grown oxide (TGO) and mismatch in thermal expansion coefficients of different layers in the TBC system. In addition to this, sintering of topcoat as well as the thermal fatigue induced by thermal cycling also plays a significant role in failure.

In this study, TCF testing was performed at Siemens Industrial Turbomachinery, Sweden. The samples were exposed to cycles of firstly isothermally heating up to dwell temperature of $1100{ }^{\circ} \mathrm{C}$ for one hour, and then cooling down to around $100{ }^{\circ} \mathrm{C}$ in ten minutes with compressed air. The samples were cycled until failure which was determined by $20 \%$ spallation of the topcoat. A photograph of the samples was recorded after each cycle to determine the failure.

Two samples of each coating set were tested by TCF testing in this study that were tested in two separate runs in order to observe the scattering between test runs.

\section{Thermal Shock Testing}

Thermal shock testing is performed to analyze the performance of TBCs under short exposures at high temperatures 
Fig. 1 Microstructure images of samples in as-sprayed condition, left: cross section and right: top view (a) YSZ, (b) DySZ, (c) YSZ/GZO, and (d) YSZ/CeYSZ. The arrows indicate cracking between the interpass layers or the two topcoat layers
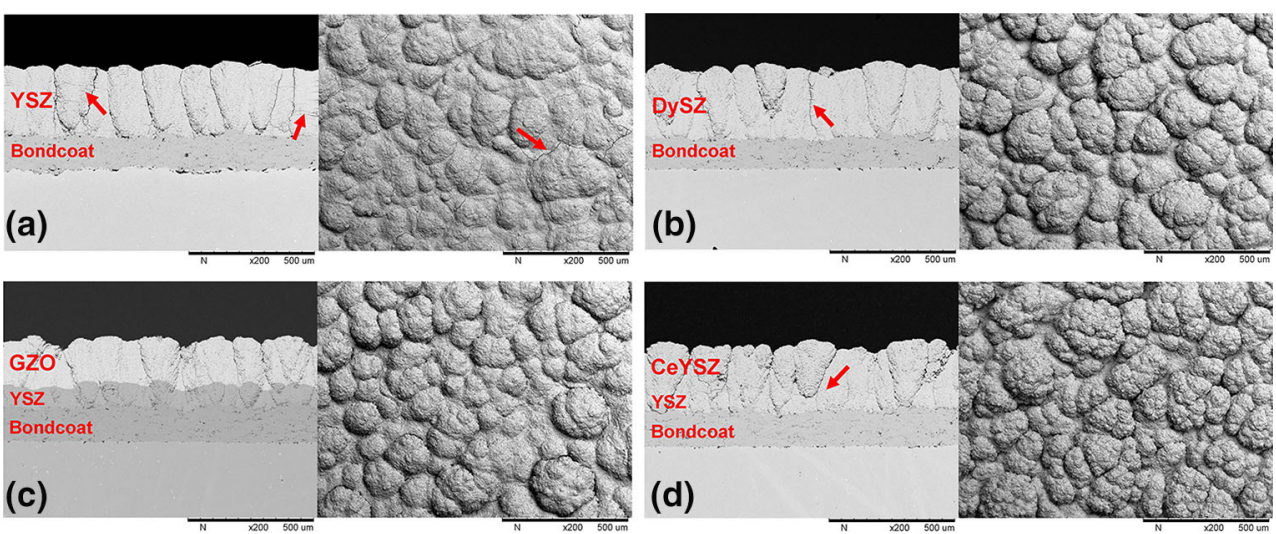

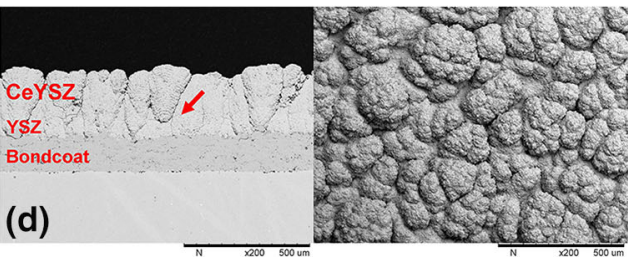

and then rapid quenching. This test normally does not allow significant TGO growth due to short exposure times at high temperatures. However, the coatings are subjected to much higher thermal gradients and transients as compared to TCF testing. The failure in thermal shock testing is mainly driven by crack propagation in the topcoat near the topcoat-bondcoat interface due to thermal mismatch between the different layers in the TBC system. Fracture toughness and strain tolerance of the topcoat play a significant role in failure as it determines the resistance of the topcoat against thermal fatigue induced by thermal cycling.

In this study, thermal shock testing was performed at GKN Aerospace, Sweden, using their burner rig testing (BRT) equipment which has been developed in-house. During this test, the samples were first exposed to heating at front surface with combustion burners for $75 \mathrm{~s}$ which resulted in topcoat surface temperatures up to $1300{ }^{\circ} \mathrm{C}$ and then cooled down to around $450{ }^{\circ} \mathrm{C}$ with compressed air in 75 s. Samples were cooled down with compressed air from the back side during the heating cycle which maintained a gradient across the sample. The samples were cycled until failure which was determined by $10 \%$ spallation of either complete topcoat or part of the topcoat layer (chipping failure). A short video of the samples was recorded after every four cycles to determine the failure.

In addition to the cycle durations, another major difference between TCF testing and BRT is that while in TCF the samples are exposed to isothermal heating, a thermal gradient is maintained across the sample during BRT.

Four samples of each coating set were tested by BRT in this study.

\section{Results and Discussion}

\section{Microstructure and Porosity}

The microstructure cross-section images along with the top surface view of the samples in as-sprayed condition are shown in Fig. 1. The single-layer topcoats YSZ and DySZ shown in Fig. 1(a) and (b) exhibited a dense columnar structure looking similar to the vertically cracked microstructure typically produced by APS. Some interpass porosity bands can be clearly distinguished in the singlelayer topcoats as indicated by arrows in the figures. Although these interpass porosity bands could be beneficial for reducing thermal conductivity of these topcoats, they could also be detrimental to coating lifetime as they could promote horizontal crack propagation during thermal cycling. The interpass porosity bands are deemed to occur due to the overspray during deposition of coatings (Ref 15). The overspray occurs due to the particles that have not been fully molten because of being treated in the plasma plume periphery which is colder than the plasma plume core, thus resulting in porous regions. These interpass porosity bands can potentially be reduced by increasing the surface velocity during deposition (Ref 15 ).

Some branching cracks between the interpass layers can also be observed in the single-layer topcoats, especially close to the column gaps indicating that stress relaxation occurred during spraying probably due to high packing density of the columns with relatively low porosity. This effect can also be observed in the top view of YSZ singlelayer topcoat as shown in Fig. 1(a) where the columns seem to be merged with each other and the column boundaries not distinctly visible. Some cracking on the surface can also be observed in the figure indicating stress relaxation during cooling. The top surface of the DySZ single-layer topcoat shown in Fig. 1(b) had a cauliflower structure as typically exhibited by SPS columnar coatings. This cauliflower structure with more distinct column gaps than the YSZ single-layer topcoat is desirable as it would result in higher strain tolerance.

The bilayer topcoats shown in Fig. 1(c) and (d) also exhibited a columnar structure with more distinct column gaps than the single-layer coatings. This can be clearly observed in both the cross-section images as well as the top view images where a typical SPS cauliflower structure can 
be seen. The columns in second layer continued to build on the columns in the first layer in both bilayer topcoats. It can be observed that the first topcoat layer is slightly denser than the second topcoat layer as intended during spraying. A denser layer is generally sprayed first as it provides resistance against detrimental crack propagation near the topcoat-bondcoat interface during thermal cycling, while the subsequent porous layer provides the necessary strain tolerance required for high lifetime of TBCs (Ref 13).

The interpass porosity bands were less distinct in the bilayer topcoats than the single-layer topcoats. However, some cracking between the interpass layers similar to the single-layer topcoats can also be observed in bilayer topcoats. The horizontal cracking is especially pronounced at the interface between the topcoat layers in YSZ/CeYSZ sample as indicated by the arrow in Fig. 1(d) implying low adhesion between the layers. The low adhesion between the layers could be due to different material properties, especially thermal expansion coefficients, and/or due to different porosities of the two layers, which result in cracking during cooling after spraying. It could also have been due to insufficient preheating of the surface before spraying the second topcoat layer. This indicates that the spray parameters may need to be optimized further for these coatings in order to remove the horizontal cracks.

The porosity of the TBCs measured by image analysis is shown in Fig. 2. It can be noted that the coarse porosity, that is porosity features larger than $2 \mu \mathrm{m}^{2}$ area measured by $500 \times$ images, was highest in the YSZ/CeYSZ sample and lowest in the YSZ sample. This effect can be both due to larger intercolumnar spaces as well as interpass porosity. However, only small differences in the coarse porosity values can be observed when considering the standard deviation. The fine porosity, that is porosity features smaller than $2 \mu \mathrm{m}^{2}$ area measured by $5000 \times$ images, can be observed to be similar in all samples with YSZ/GZO showing slightly higher fine porosity value. The total porosity values show that the bilayer topcoats had a higher porosity than the single-layer topcoats; however, the

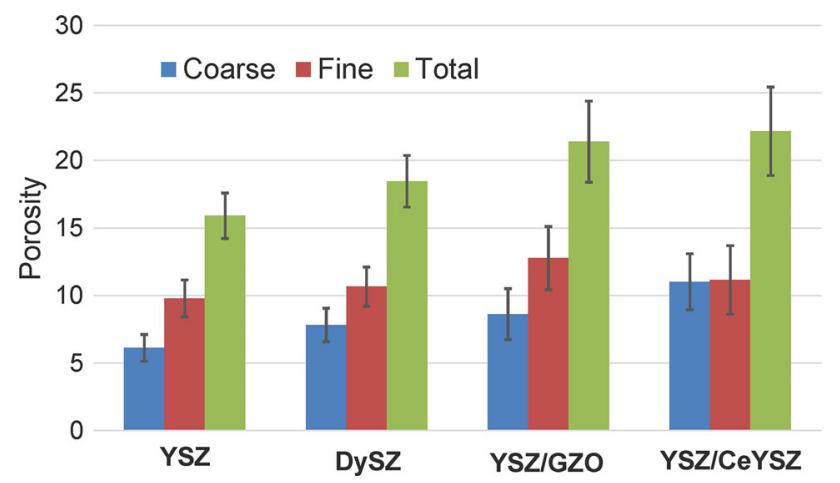

Fig. 2 Porosity in as-sprayed state evaluated by image analysis maximum difference in average values (between YSZ/ CeYSZ and YSZ) was only about 5\%. This result shows that using the same parameters (except spray distance) for all topcoats result in slightly different microstructures.

\section{Thermal Cyclic Fatigue Testing}

The results from the TCF testing are shown in Fig. 3. Between the single-layer topcoats, DySZ showed around $20 \%$ higher TCF lifetime than YSZ in TCF testing. This result shows that in addition to potentially providing reduced thermal conductivity, stabilizing zirconia with dysprosia instead of yttria could also result in higher TCF lifetime as observed previously in case of APS TBCs (Ref 23). The higher lifetime of DySZ than YSZ could also be attributed to the difference in as-sprayed microstructures as discussed in "Microstructure and Porosity" section where a more strain tolerant cauliflower structure was observed for the DySZ coating as compared to the indistinct column spaces in the YSZ coating resulting in lower strain tolerance. Between the bilayer topcoats, YSZ/CeYSZ showed a better TCF lifetime than YSZ/GZO which was only slightly below YSZ/CeYSZ, especially when considering the variation between the samples. All topcoats with advanced materials showed a higher TCF lifetime than single-layer YSZ topcoat.

The microstructure images of all coatings after failure in TCF testing are shown in Fig. 4. A dark gray layer of TGO with thickness in the range of $6-8 \mu \mathrm{m}$ can be observed in all coatings. It can be clearly noted in Fig. 4 that failure occurred due to cracking near the topcoat-bondcoat interface in all coatings. Even though some cracks can be observed between the topcoat layers in the double-layer topcoat samples, these cracks were not the major failure mode. This indicates that the failure was driven by, as also discussed in "Porosity Measurement" section, crack propagation due to TGO growth and thermal mismatch between different layers during thermal cycling. Both of these phenomenons induce high stresses in the topcoat near

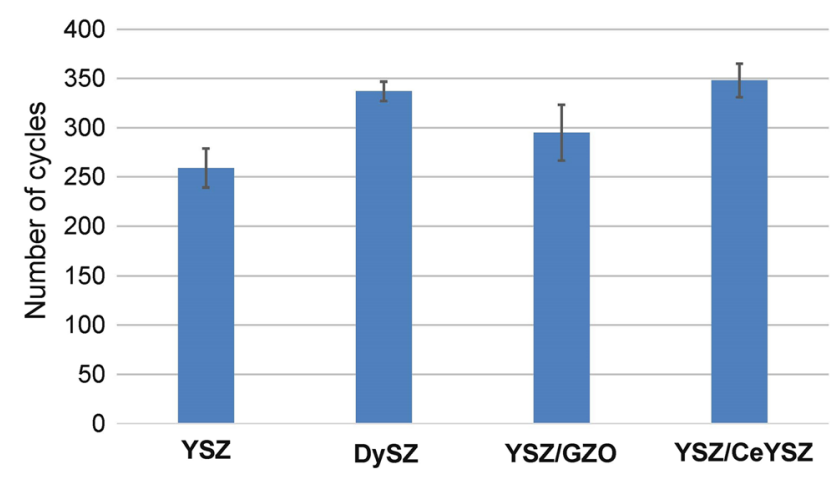

Fig. 3 Thermal cyclic fatigue lifetime results 
Fig. 4 Microstructure images of samples after TCF testing (a) YSZ, (b) DySZ, (c) YSZ/ GZO, and (d) YSZ/CeYSZ. The remaining beta-phase layer is indicated in (a) and (c)

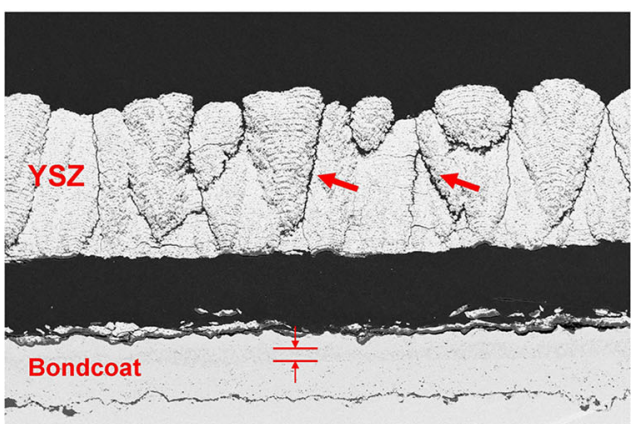

(a)
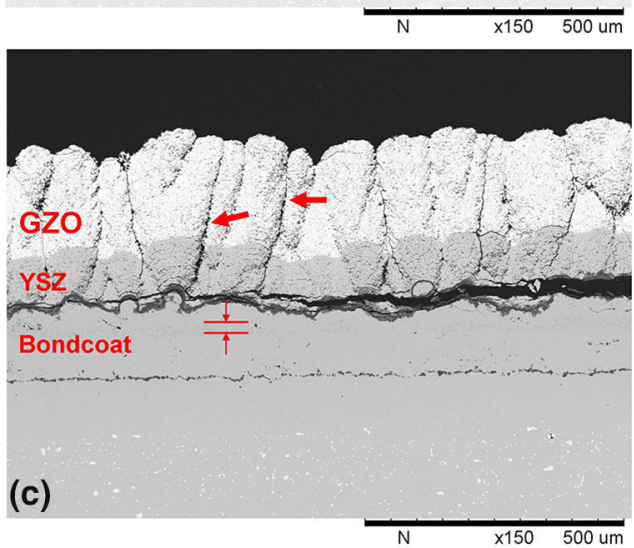

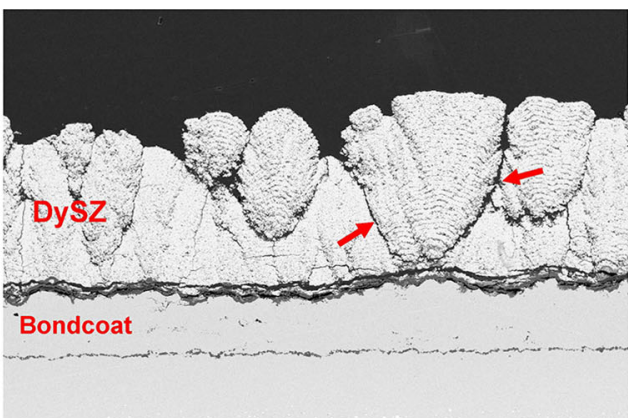

(b)

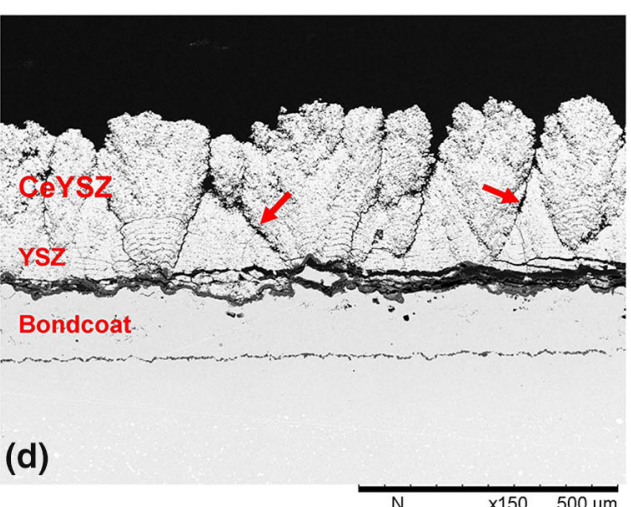

the topcoat-bondcoat interface resulting in cracking and thus failure (Ref 24). It can be noticed in Fig. 4 that cracking occurred through the interpass porosity bands closest to the topcoat-bondcoat interface in all cases, suggesting clearly that the interpass porosity bands provide a path of least resistance for crack propagation. This failure mechanism in TCF testing has also been observed in previous work done on SPS coatings (Ref 25). These results show that formation of interpass porosity should be avoided, especially near the topcoat-bondcoat interface in order to avoid detrimental crack propagation and thus increase TBC lifetime.

Opening up of column gaps after TCF testing can be observed in Fig. 4 in several regions as also indicated by the arrows. This phenomenon has also been observed in previous works (Ref 16, 21) and is understood to occur due to the sintering of ceramic material because of exposure to high temperatures for long durations in TCF testing. Sintering of the fine particles in coating results in reduction in the intra-columnar porosity and thus shrinkage of the column (Ref 16, 21). Shrinkage of the columns due to sintering is not desired as it could induce cracking in the coating resulting in lower lifetime (Ref 16).

Another feature that can be noted in the microstructure images shown in Fig. 4 is that the beta-phase is completely depleted in DySZ and YSZ/CeYSZ samples after the TCF testing. This shows that the bondcoat reached the end of its lifetime as it could not facilitate the formation of the slow growing alumina scale any longer. After complete betaphase depletion, other oxides such as spinel oxides, chromia, nickel oxide form rapidly and induce very high stresses resulting in chemical failure of the TBC system (Ref 24). In the case of YSZ and YSZ/GZO samples, a very thin layer of beta-phase can still be observed as also indicated in the figures. It can be concluded from these observations that all topcoats survived almost until the end of the chemical lifetime of their bondcoats. Therefore, for improvement in TCF lifetime of these TBCs, apart from improvements in topcoat microstructures, either the bondcoat thickness should be increased so as to enlarge the aluminum reservoir in the bondcoat or the bondcoat/substrate chemistry should be modified to reduce the rate of interdiffusion.

\section{Thermal Shock Testing}

The results from thermal shock testing are shown in Fig. 5. Between the single-layer topcoats, similar to the TCF lifetime results, DySZ showed higher average lifetime than YSZ in BRT. This result again implies that dysprosia may be a suitable alternative to YSZ providing both lower thermal conductivity and longer lifetime; however, further trials will be required to reach a decisive conclusion due to the standard deviation among the samples in this case. Between the bilayer topcoats, YSZ/GZO showed better BRT lifetime by far as compared to YSZ/CeYSZ which 
showed even lower average lifetime than the single-layer topcoats.

The microstructure images of all coatings after failure in BRT are shown in Fig. 6. The thickness of TGO in case of BRT was observed to be $1-2 \mu \mathrm{m}$ showing that unlike TCF testing, the oxide growth did not have a significant influence on failure in BRT.

It can be observed that failure in the single-layer topcoat samples occurred due to cracking in the topcoat near the topcoat-bondcoat interface. This type of failure is typically expected from BRT and indicates that the failure in singlelayer topcoats was driven by crack propagation near the topcoat-bondcoat interface due to high thermal gradients

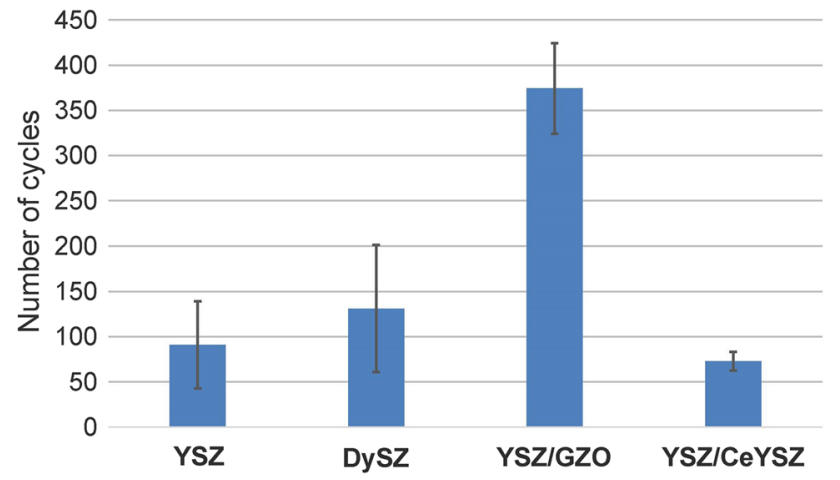

Fig. 5 Burner rig testing lifetime results
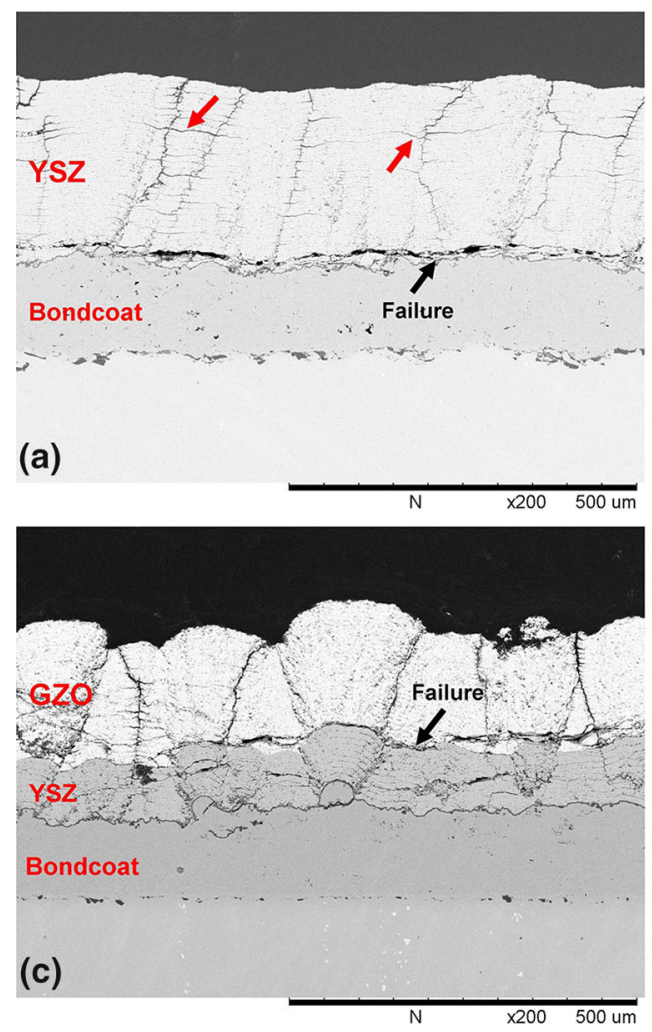

Fig. 6 Microstructure images of samples after burner rig testing (a) YSZ, (b) DySZ, (c) YSZ/GZO, and (d) YSZ/CeYSZ (b)

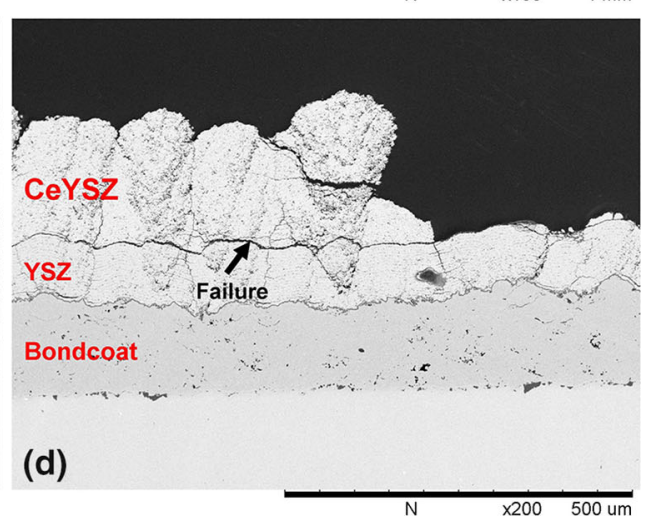

and thermal mismatch stresses induced during thermal cycling. Cracking through the interpass porosity bands close to the topcoat-bondcoat interface can be observed in both single-layer topcoats similar to the microstructure after TCF testing shown in Fig. 4. Some cracking through the interpass porosity bands across the coating thickness in YSZ topcoat shown in Fig. 6(a) can also be observed. Even though these horizontal cracks were not the major cause of failure in this case, they could also be detrimental as they could lead to chipping failure of the topcoat. These results show again that formation of interpass porosity should be avoided, especially near the topcoat-bondcoat interface in order to avoid detrimental crack propagation.

Failure in the bilayer topcoats YSZ/GZO and YSZ/ CeYSZ shown in Fig. 6(c) and (d) occurred mainly in the second topcoat layer close to the interface between the two topcoat layers. This failure mode has also been observed in previous work done on multilayered TBCs produced by SPS (Ref 20) and is understood to occur due to the lower fracture toughness of GZO and CeYSZ as compared to YSZ promoting crack propagation in the second topcoat layer near the interface between the two topcoat layers instead of cracking in YSZ near the topcoat-bondcoat interface. Dai et al. studied the influence of thickness of YSZ coating followed by lanthanum zirconate (LZ) layer, both deposited by APS, as a double-layer topcoat on BRT

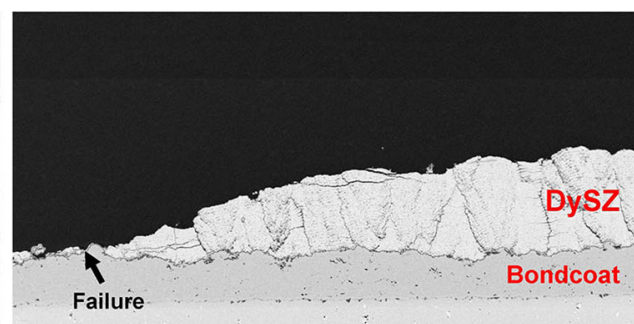


lifetime. They found that the TBC lifetime was significantly increased when the thickness of YSZ layer was higher than $100 \mu \mathrm{m}$ (Ref 26). Moreover, while the failure location after testing for YSZ thickness less than $100 \mu \mathrm{m}$ was in the LZ layer near the YSZ-LZ interface, the failure location for YSZ thickness more than $100 \mu \mathrm{m}$ shifted to YSZ layer near the YSZ-bondcoat interface (Ref 26). The reason for this behavior was that only a thick enough YSZ layer was able to effectively reduce the thermal stress and the driving force for crack extension (Ref 26). Since in this study the YSZ layer thickness in double-layer topcoats was $100 \mu \mathrm{m}$, a higher YSZ thickness could potentially improve the BRT lifetime and shift the failure location near the YSZ-bondcoat interface. However, this would have to be done either at the cost of reducing the thickness of the second topcoat layer with enhanced thermal properties or increasing the total topcoat thickness. Further trials will be needed to test this hypothesis that could move the failure location from the bilayer interface to the topcoat-bondcoat interface as normally desired for high cyclic lifetime.

Figure 7 shows the microstructure images at high magnification before and after BRT in YSZ single-layer topcoat and the GZO layer in the YSZ/GZO double-layer topcoat. It can be observed in both samples that sintering occurred during BRT resulting in reduction in porosity. Healing of micro-cracks resulting in a chain of spherical pores as well as reduction in size of pores can be observed in both cases, some of which are indicated by the arrows. The healing of micro-cracks after exposure to high temperatures has also been observed in previous work done on APS coatings (Ref 27). This result shows that both YSZ and YSZ/GZO underwent significant amount of sintering during BRT indicating that sintering was not a factor for high BRT lifetime of YSZ/GZO coating.

The reason for significantly higher BRT lifetime of YSZ/GZO topcoat is thus deemed to be its lower thermal conductivity that could provide better thermal protection due to higher thermal gradient across the topcoat and prolonged phase stability at high temperatures during BRT (Ref 7, 23).

The reason for low BRT lifetime of YSZ/CeYSZ topcoat could have been the poor adhesion between the topcoat layers in the as-sprayed state as indicated by the cracks in Fig. 1(d). These cracks could have easily propagated during BRT resulting in early failure of the coating. The higher porosity of YSZ/CeYSZ topcoat as shown in Fig. 2 could also be another reason as higher porosity would generally result in lower toughness that would be more susceptible to cracking. These effects were not observed during TCF testing as failure in TCF testing is mainly driven by crack propagation due to the slow growing TGO layer and mismatch in thermal expansion coefficients of
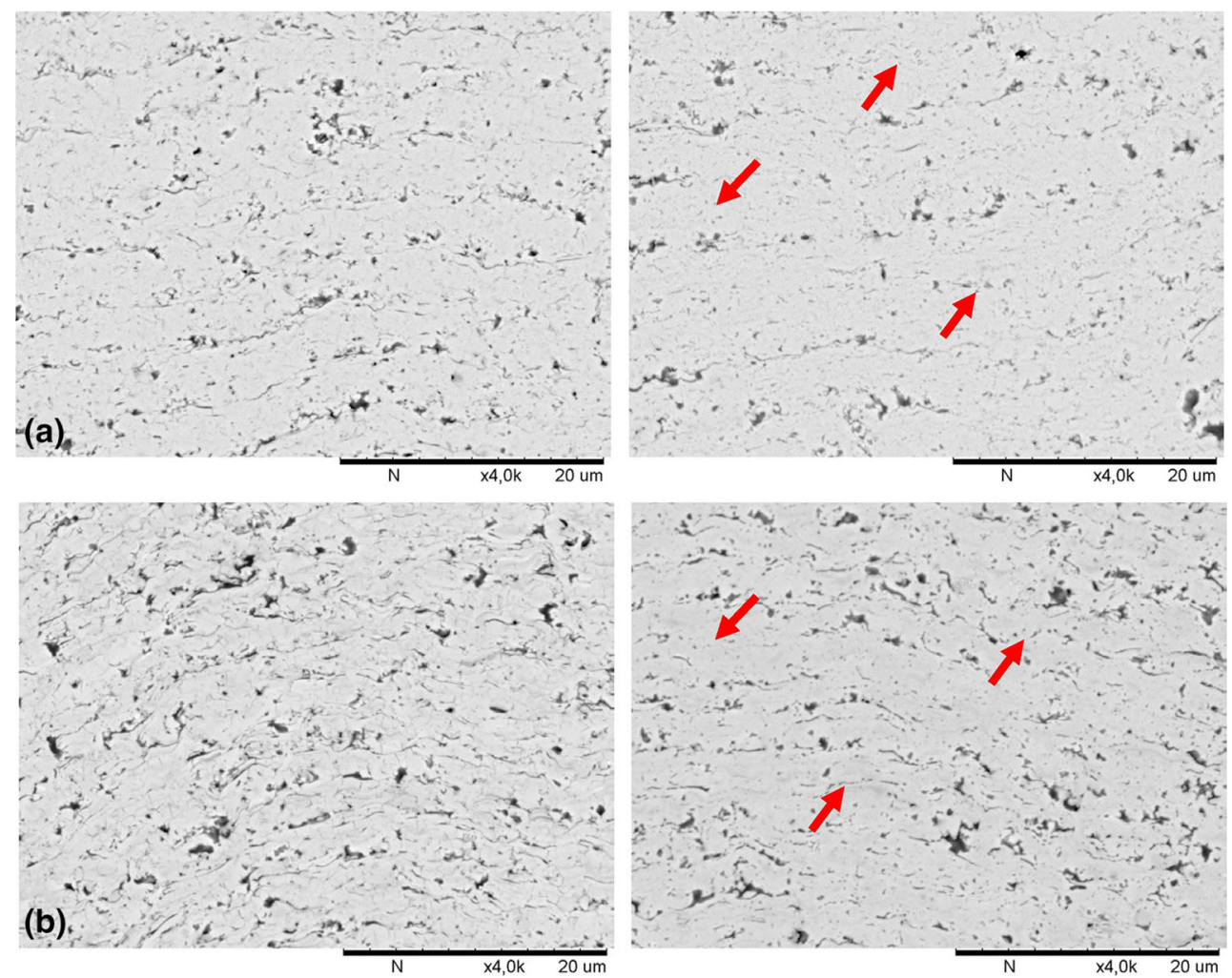

Fig. 7 Microstructure images of samples, left: in as-sprayed condition and right: after burner rig testing (a) YSZ and (b) GZO layer in YSZ/GZO 
different layers in the TBC system making the topcoatbondcoat interface the major failure zone. However, in BRT, where the samples are exposed to much shorter cycle times and high temperature gradients, the lifetime is significantly dependent on the fracture toughness of the topcoat and failure occurs mainly in the topcoat slightly above the topcoat-bondcoat interface making the effect of topcoat microstructure more dominant in this case.

\section{Summary and Conclusions}

In this work, single-layer and bilayer topcoat architectures deposited by SPS for TBCs were investigated. Lifetime of these samples was determined by thermal cyclic fatigue testing and thermal shock testing. The microstructure of assprayed and failed samples was investigated and the failure mechanisms in each case were discussed.

The failure mode in TCF testing was cracking near the topcoat-bondcoat interface in all cases. In BRT, in singlelayer topcoats, cracking occurred near the topcoat-bondcoat interface while in bilayer topcoats, failure occurred in the upper topcoat layer near the interface between the two topcoat layers due to lower fracture toughness of the second topcoat layer.

The lifetime results show that SPS seems to be a promising route to deposit multilayered TBCs for hightemperature applications. YSZ/GZO showed the best lifetime results when considering both TCF and BRT. The reason for the good performance of YSZ/GZO topcoat was deemed to be high fracture toughness of YSZ combined with low thermal conductivity and comparable thermal expansion coefficient of GZO. Further tests need to be performed in order to fully assess the performance of these materials.

Acknowledgments The authors would like to acknowledge the Knowledge Foundation for the funding of this research work. Thanks to Stefan Björklund and Kenneth Andersson at University West for the help with spraying and metallographic preparation, respectively.

Open Access This article is distributed under the terms of the Creative Commons Attribution 4.0 International License (http://crea tivecommons.org/licenses/by/4.0/), which permits unrestricted use, distribution, and reproduction in any medium, provided you give appropriate credit to the original author(s) and the source, provide a link to the Creative Commons license, and indicate if changes were made.

\section{References}

1. R. Vassen, A. Stuke, and D. Stöver, Recent Developments in the Field of Thermal Barrier Coatings, J. Therm. Spray Technol., 2009, 18(2), p 181-186
2. C.U. Hardwicke and Y.-C. Lau, Advances in Thermal Spray Coatings for Gas Turbines and Energy Generation: A Review, $J$. Therm. Spray Technol., 2013, 22(5), p 564-576

3. A. Cipitria, I.O. Golosnoy, and T.W. Clyne, A sintering model for plasma-sprayed zirconia TBCs. Part I: Free-Standing Coatings, Acta Mater., 2009, 57(4), p 980-992

4. J.M. Drexler, A.L. Ortiz, and N.P. Padture, Composition Effects of Thermal Barrier Coating Ceramics on Their Interaction with Molten Ca-Mg-Al-Silicate (CMAS) Glass, Acta Mater., 2012, 60(15), p 5437-5447

5. X.Q. Cao, R. Vassen, and D. Stoever, Ceramic Materials for Thermal Barrier Coatings, J. Eur. Ceram. Soc., 2004, 24(1), p 110

6. D. Zhu and R.A. Miller, Development of Advanced Low Conductivity Thermal Barrier Coatings, Int. J. Appl. Ceram. Technol., 2004, 1(1), p 86-94

7. R. Vaßen, M.O. Jarligo, T. Steinke, D.E. Mack, and D. Stöver, Overview on Advanced Thermal Barrier Coatings, Surf. Coat. Technol., 2010, 205, p 938-942

8. E. Bakan, D.E. Mack, G. Mauer, and R. Vaßen, Gadolinium Zirconate/YSZ Thermal Barrier Coatings: Plasma Spraying, Microstructure, and Thermal Cycling Behavior, J. Am. Ceram. Soc., 2014, 97(12), p 4045-4051

9. X. Zhong, H. Zhao, C. Liu, L. Wang, F. Shao, X. Zhou, S. Tao, and C. Ding, Improvement in Thermal Shock Resistance of Gadolinium Zirconate Coating by Addition of Nanostructured Yttria Partially-Stabilized Zirconia, Ceram. Int., 2015, 41(6), p 7318-7324

10. K.S. Lee, D.H. Lee, and T.W. Kim, Microstructure Controls in Gadolinium Zirconate/YSZ Double Layers and Their Properties, J. Ceram. Soc. Jpn., 2014, 122(1428), p 668-673

11. V. Viswanathan, G. Dwivedi, and S. Sampath, Engineered Multilayer Thermal Barrier Coatings for Enhanced Durability and Functional Performance, J. Am. Ceram. Soc., 2014, 97(9), p 2770-2778

12. V. Viswanathan, G. Dwivedi, and S. Sampath, Multilayer, Multimaterial Thermal Barrier Coating Systems: Design, Synthesis, and Performance Assessment, J. Am. Ceram. Soc., 2015, 98(6), p $1769-1777$

13. A. Ganvir, N. Curry, S. Björklund, N. Markocsan, and P. Nylén, Characterization of Microstructure and Thermal Properties of YSZ Coatings Obtained by Axial Suspension Plasma Spraying (ASPS), J. Therm. Spray Technol., 2015, 24(7), p 1195-1204

14. B. Bernard, A. Quet, L. Bianchi, A. Joulia, A. Malié, V. Schick, and B. Rémyd, Thermal Insulation Properties of YSZ Coatings: Suspension Plasma Spraying (SPS) Versus Electron Beam Physical Vapor Deposition (EB-PVD) and Atmospheric Plasma Spraying (APS), Surf. Coat. Technol., 2017, 318, p 122-128

15. N. Curry, K. VanEvery, T. Snyder, and N. Markocsan, Thermal Conductivity Analysis and Lifetime Testing of Suspension Plasma-Sprayed Thermal Barrier Coatings, Coatings, 2014, 4(3), p 630-650

16. M. Gupta, N. Markocsan, X.-H. Li, and R. Peng, Improving the Lifetime of Suspension Plasma Sprayed Thermal Barrier Coatings, Surf. Coat. Technol., 2017, 332, p 550-559

17. M. Gupta, C. Kumara, and P. Nylén, Bilayer Suspension Plasma Sprayed Thermal Barrier Coatings with Enhanced Thermal Cyclic Lifetime-Experiments and Modelling, J. Therm. Spray Technol., 2017, 26(6), p 1038-1051

18. S. Mahade, N. Curry, S. Björklund, N. Markocsan, and P. Nylén, Thermal Conductivity and Thermal Cyclic Fatigue of Multilayered $\mathrm{Gd}_{2} \mathrm{Zr}_{2} \mathrm{O}_{7} / \mathrm{YSZ}$ Thermal Barrier Coatings Processed by Suspension Plasma Spray, Surf. Coat. Technol., 2015, 283, p 329336

19. S. Mahade, N. Curry, S. Björklund, N. Markocsan, and P. Nylén, Failure Analysis of Gd2Zr2O7/YSZ Multi-layered Thermal 
Barrier Coatings Subjected to Thermal Cyclic Fatigue, J. Alloys Compd., 2016, 689, p 1011-1019

20. S. Mahade, N. Curry, S. Björklund, N. Markocsan, P. Nylén, and R. Vaßen, Functional Performance of $\mathrm{Gd}_{2} \mathrm{Zr}_{2} \mathrm{O}_{7} / \mathrm{YSZ}$ Multi-layered Thermal Barrier Coatings Deposited by Suspension Plasma Spray, Surf. Coat. Technol., 2017, 318, p 208-216

21. A. Ganvir, N. Markocsan, and S. Joshi, Influence of Isothermal Heat Treatment on Porosity and Crystallite Size in Axial Suspension Plasma Sprayed Thermal Barrier Coatings for Gas Turbine Applications, Coatings, 2017, 7(4), p 1-14

22. J. Schindelin, I. Arganda-Carreras, E. Frise et al., Fiji: An OpenSource Platform for Biological-Image Analysis, Nat. Methods, 2012, 9(7), p 676-682

23. N. Curry, N. Markocsan, L. Östergren, X.-H. Li, and M. Dorfman, Evaluation of the Lifetime and Thermal Conductivity of Dysprosia-Stabilized Thermal Barrier Coating Systems, J. Therm. Spray Technol., 2013, 22(6), p 864-872
24. A.G. Evans, D.R. Mumm, J.W. Hutchinson, G.H. Meier, and F.S. Pettit, Mechanisms Controlling the Durability of Thermal Barrier Coatings, Prog. Mater Sci., 2001, 46(5), p 505-553

25. N. Curry, K. VanEvery, T. Snyder, J. Susnjar, and S. Bjorklund, Performance Testing of Suspension Plasma Sprayed Thermal Barrier Coatings Produced with Varied Suspension Parameters, Coatings, 2015, 5, p 338-356

26. H. Dai, X. Zhong, J. Li, Y. Zhang, J. Meng, and X. Cao, Thermal Stability of Double-Ceramic-Layer Thermal Barrier Coatings with Various Coating Thickness, Mater. Sci. Eng., A, 2006, 433, p 1-7

27. N. Curry, N. Markocsan, X.-H. Li, A. Tricoire, and M. Dorfman, Next Generation Thermal Barrier Coatings for the Gas Turbine Industry, J. Therm. Spray Technol., 2011, 20(1-2), p 108-115 